\title{
Internet-based support for infertile patients: a randomized controlled study
}

\author{
K. Haemmerli $\cdot$ H. Znoj · T. Berger
}

Received: April 23, 2009/Accepted: December 14, 2009/Published online: December 29, 2009

(C) Springer Science+Business Media, LLC 2009

\begin{abstract}
This study aimed to evaluate the efficacy and patient acceptance of the first German-language Internetbased treatment for infertile patients. Infertile patients $(N=124)$ were randomly assigned to either an 8 -week Internet-based cognitive-behavioral treatment, or to a waiting-list control group. Participants were assessed at treatment start, post-treatment, and at a 5-month follow-up. Outcome measures included mental health and pregnancy rate. From pre- to posttest, treated participants in contrast to controls did not show significant improvement, although between-group effect sizes were in favor of the intervention group on all mental health measures (Cohen's d ranged from 0.16 to 0.38 ). The intervention significantly reduced the depression level of clinically distressed and depressed participants. No effects were found regarding pregnancy rate. The treatment was assessed as positive or very positive by $80 \%$ of the participants; this finding coupled with the high demand for such support confirm that Internetbased interventions are a promising new approach for infertile patients that needs more development and testing.
\end{abstract}

Keywords Infertility - Internet-based treatment . Mental health · Assisted reproduction - Cognitive behavior therapy

K. Haemmerli $(\bowtie) \cdot H$. Znoj · T. Berger Institute of Psychology, Department of Clinical Psychology and Psychotherapy, University of Bern, Gesellschaftsstrasse 49, 3012 Bern, Switzerland

e-mail: katja.haemmerli@ptp.unibe.ch

\section{Introduction}

Infertility and its medical treatment are very stressful. For a variety of reasons, including fears of being dismissed from treatment by reproductive endocrinologists, some affected infertile patients do not participate in psychological interventions. Several studies have reported high levels of mental distress among infertile patients (Chen et al. 2004; Eugster and Vingerhoets 1999; Wischmann 2005). Nevertheless, infertile patients usually do not differ from the general population in terms of mental distress levels, nor report mental distress for reasons such as maintaining social desirability (Covington and Burns 2006; DunkelSchetter and Lobel 1991).

Psychological interventions have proven effective for infertile patients in improving mental health and increasing pregnancy rates (Boivin 2003; De Liz and Strauss 2005; Haemmerli et al. 2009). However, psychological support is rarely offered until medical treatment is sought (Cousineau and Domar 2007). Assisted reproductive treatments (ART) are often considered to be the most stressful way of treating infertility (Eugster and Vingerhoets 1999). Evidence has been found for the efficacy of psychological interventions in improving pregnancy rates among infertile non-ART patients (Haemmerli et al. 2009). Offering psychological interventions in advance of fertilization treatments may reduce the number of treatment cycles patients require to achieve pregnancy (Campagne 2006). Provision of psychological support could reduce the high dropout rate from medical treatment on the part of infertile patients with high levels of distress (Verberg et al. 2008).

Despite the overwhelming opinion of researchers and practitioners as to the importance and potential benefits of psychological interventions for infertility patients, very few such patients actually take advantage of psychological 
support when it is made available to them (Boivin et al. 1999; Wischmann 2005). The low utilization of psychological interventions may be attributed to fears of stigmatization surrounding acceptance of such support, to skepticism regarding efficacy, and to fears of emotional destabilization (Wischmann 2008). Since less distressed infertile patients often cope successfully with the strains of infertility on their own, psychological interventions should be offered to patients suffering from high levels of distress (Boivin et al. 1999). Psychological interventions may help reduce infertile patients' levels of anxiety, depression, infertility-specific distress, and may improve certain target (for example, sexual) behavior (Boivin 2003; De Liz and Strauss 2005).

An increasing number of infertile patients look to printed materials or surf the World Wide Web for information and support (Cousineau and Domar 2007). The Internet, which offers the possibility of anonymous communication, is often considered less stigmatizing than face-to-face psychological support. A vast amount of information about infertility and numerous self-help forums exist on the World Wide Web. More than half of all infertile patients seek out fertility-related information on the Internet, and many of them consider the information available and the opportunity for anonymous exchange to be of help (Himmel et al. 2005; Kahlor and Mackert 2009). However, studies evaluating the quality of fertility clinic websites have concluded that they are often inadequate (Huang et al. 2005; Okamura et al. 2002). For example, such health-related websites must become transparent as to their sources and ensure that the information they present is appropriate, independent, and timely (HONcode 2009).

To the best of our knowledge, only one Internet-based psychological treatment program for infertile patients has been evaluated to date (Cousineau et al. 2008). This brief (60-90-min) educative, stress-management program was shown to decrease infertility-specific distress and increase self-efficacy among infertile women undergoing medical treatment. The Child Wish Online Coaching program evaluated in the present study is the first Internet-based German language treatment. Compared with the Internetbased treatment of Cousineau et al. (2008), Child Wish Online Coaching is longer in duration (30-60 min per session over 8 weeks), includes both infertile women and men independent of their current medical treatment, and is primarily based on principles of cognitive-behavioral therapy. To date, only a handful of studies have examined mental health among infertile men, but these have shown that infertile men also suffer from high levels of mental distress (Cousineau and Domar 2007).

The main purpose of the randomized controlled trial described here was to examine the efficacy of Online Coaching with regards to mental health (depression, anxiety, and infertility-specific distress) and pregnancy rate by comparing an intervention group with a waiting-list control group. We further examined if the effects found in the intervention group were still present at a 5-month follow-up, and, for exploratory purposes, we evaluated the responses of participants in the waiting-list control group once they received the treatment themselves. In exploratory analyses we evaluated the efficacy of the program for patients with clinically relevant levels of distress or depression. The final aim of the study was to examine patients' overall acceptance and usage of the Child Wish Online Coaching program.

\section{Methods}

Participant eligibility and recruitment

Participants were recruited through the University of Bern, Switzerland, by means of articles in regional newspapers and advertisements in Swiss and German fertility websites. Approval for the study was obtained from the Cantonal Research Ethics Committee of Bern, Switzerland. Recruitment took place between March 2008 and May 2008. Informed consent was obtained in writing from all participants.

Individuals were eligible to participate in the study if they met the following criteria for inclusion: (a) women and men suffering from primary or secondary infertility for at least 1 year (the definition of infertility recommended by the World Health Organization [WHO 2002]); (b) not undergoing any other psychological treatment for the duration of the study; (c) having access to a computer with an Internet connection; and, (d) at least 18 years of age. Our website provided general information about infertility and its medical treatment as well as an outline of the study and the criteria for participation. This information was accessible to anyone. After registering participants, mailings were sent out via the postal service that contained further information about the study, copies of the documents confirming informed consent, and the various baseline questionnaires. Following a final check of eligibility, participants received a login name and password in order to enter the secured client zone and begin the treatment. Over the course of the entire recruitment and intervention process, contact with the patients was limited to email contact and correspondence via the postal service, with no face-toface contact occurring at any point.

\section{Procedure}

One hundred and forty-four participants met all the inclusion criteria and were randomized to the treatment 
group $(n=60)$ or waiting-list control group $(n=64)$ using an online randomization program (Randomization.com 2008). A total of 124 participants were regarded as providing sufficient power for later statistical analyses. Figure 1 presents participant flow through the study. If a couple registered for Online Coaching, both partners were randomly assigned as a pair to either of the study conditions-11 couples were assigned to the intervention group and 10 couples were assigned to the control group. All of the male participants were married to another participant. Participating as a couple was treated as a potential confounding variable. After 8 weeks, the intervention and the waiting-list control group completed another assessment, and the waiting list control group began with the treatment. Only 14 people (5 in the treatment group and 9 in the control group) dropped out between pre- and post-assessment and failed to complete postassessment questionnaires (11.3\%). Of the five participants in the treatment group who did not complete post-assessment questionnaires, one participant indicated having insufficient time and four participants did not provide any reason. In the control group: six participants became pregnant during the waiting period; one participant wanted to start the Online Coaching program at a later date; one woman's partner fell ill; and one participant no longer wanted to participate following randomization. Further, three participants belonging to the intervention group and two participants belonging to the control group were excluded from the analyses since they had received psychological treatment between the preand post-assessments. Following an intention-to-treat paradigm, we set the post-test data for the non-completers at their baseline pre-test level.

The intervention group was assessed once more at a 5-month follow-up, 3 months after the post-assessment. Eighty percent $(n=48)$ of the 60 participants in the treatment condition returned the mailed follow-up questionnaires and completed all three assessments. The control group also completed a post-assessment after receiving the 8 -week treatment. A total of 11 participants from the control group did not complete the post-treatment questionnaire: five participants got pregnant during the waiting phase and completed a questionnaire after that phase, but never started the actual intervention; two participants no longer wished to take part in the study; and, four remaining participants dropped out due to differing preconceptions of Online Coaching, family illness, or unknown reasons.

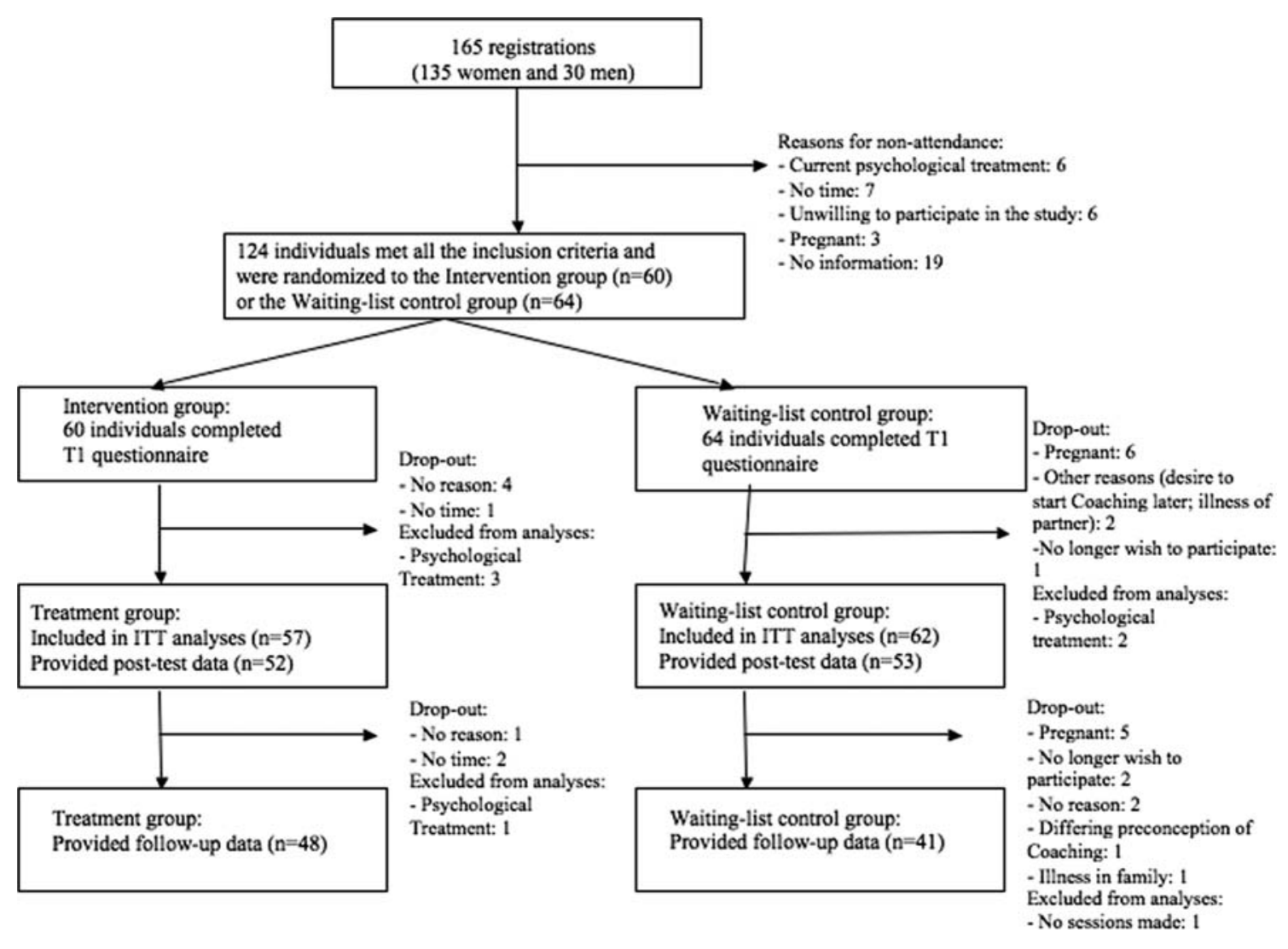

Fig. 1 Participant flow 


\section{Intervention}

The Child Wish Online Coaching program's goal is to improve the mental health of the infertile patients who participate, not solely or primarily to increase their pregnancy rate. The intervention consists of an 8-week Internetbased program encompassing an interactive self-help guide, a module for patients to establish regular text-based contact with a therapist, a continuous monitoring and feedback system examining patients' responses, as well as collaborative elements and forums that offer participants the opportunity to share their experiences with other patients. We employ SSL (Secure Sockets Layer) encryption to secure all Internet-based communication and participants are identified using anonymous login names and passwords.

The content of the self-help guide is primarily based on principles of cognitive behavioral therapy and well-established treatment topics for infertile patients (for example, Bents 1991), and is further supplemented with clarificationoriented therapy techniques (for example, Sachse 2003; session 1 emphasizes clarifying the motives behind the wish for a child) and system therapy (for example, Stammer et al. 2004; session 11 emphasizes tracing a couple's path together and thinking about the impact of infertility on their partnership). The Child Wish Online Coaching program consists of a total of 108 web pages divided into 13 sessions. Participants are free to decide the pace at which they complete the sessions, and they are granted access to the sessions beyond the official duration of the Online Coaching program.

In the first session, participants are advised to clarify and modify their motives, hopes, and fears concerning their wish for a child as well as any unrealistic expectations they might have (for example, Stammer et al. 2004). The goal of the second session of the intervention program is for patients to analyze their own stress and to better understand what contributes to it. In the third session, participants are taught different ways of coping with stress and learn new strategies for coping with stress in everyday life (Kaluza 2004). Several studies have indicated a positive effect of relaxation exercises on mental distress (for example, Chan et al. 2006) and on pregnancy rate (for example, Levitas et al. 2006). In the fourth session, progressive muscle relaxation (PMR; Jacobson 1938) is introduced as a further strategy for reducing stress. Infertility and its medical treatment are often described as an emotional rollercoaster. In the fifth session, participants receive various information and strategies for coping with stressful feelings. The goal of the sixth session is for patients to learn how to better handle unpleasant reactions and comments from those around them, and how to identify an appropriate policy on sharing information about their infertility with others
(Wischmann and Stammer 2006). Goals of the seventh session include encouraging patients to pay closer attention to what they enjoy and to integrate it more frequently into everyday life. The goal of the eighth session is for couples to achieve an understanding of their differences and to find ways of realizing the needs of both partners (Wischmann and Stammer 2006). Additional topics in this session include learning rules for better communication and introducing a time for talking about each other's desire for a child. The ninth session focuses on participants' lives before trying to conceive a child. Once the period of intensive effort towards having a child begins, earlier positive activities and contacts can often go neglected and should be reactivated. In the tenth session, participants are encouraged to clarify their anxieties and fears surrounding medical treatment and to consider the possibility of having a positive experience with such treatment (Covington and Burns 2006). They receive practical tips regarding medical treatment and communication with medical staff. The eleventh session targets realizing the strengths inherent to each couple's relationship as well as future projects they might share independent of their wish for a child. The period of waiting between embryo transfer, pregnancy test, and result is often described as the most stressful (Boivin and Takefman 1995; Klonoff-Cohen et al. 2001). In the twelfth session, participants receive tips onto how to organize the periods of waiting and how to handle a negative pregnancy test. The aims of the thirteenth session include establishing effective self-support and strengthening self-esteem.

Each web page and each session builds upon the previous, and users only gain access to the next site once they have completed all the previous sites and tasks. However, since many tasks and exercises are repeated, working through the self-help guide is not simply a matter of sequential progression. A final section following the thirteenth session focuses on consolidation of skills. It emphasizes the importance of practice and asks participants to repeat several of the exercises and tasks introduced in previous sessions.

At the end of every session (with the exception of sessions 2 and 13), participants have the opportunity to share their experiences with other participants in the context of forums. Examples of themes from the 11 forums include exploring the meaning of one's desire for a child, coping with stress, enjoying life and feeling good, and medical treatment. Posts to the forums are kept anonymous and are monitored by therapists. In addition, throughout the course of the program, participants are given the option of anonymously publishing their own responses regarding the history of their wish for a child, their stress models, and their ways of coping with stress. 
Child Wish Online Coaching is a treatment that involves minimal contact with therapists. When patients log into the program for the first time, they are redirected to the contact module, where they are introduced to a therapist and informed that they may contact this therapist at any time. These therapists respond to patients within 2 days of receiving their messages. Participants may contact their therapists via email to express their feelings, discuss a particular topic, or request advice. About $65 \%$ of the participants wrote messages to their therapist. In addition, these therapists are instructed to write brief, motivational messages to the patients once a week, encouraging them to proceed with the sessions. In our trial, the mean number of messages written by patients was 4.2 (Min: 0; Max: 19), with individual messages averaging 156 words in length. Contact between the participants and the therapists occurred exclusively via the Internet.

\section{Therapists}

There were three female therapists involved: one psychologist bearing a master's degree in clinical psychology and two postgraduate students of psychology. The first therapist, who has combined a postgraduate course of studies in clinical psychology together with psychotherapy and is highly experienced in treating infertile patients, trained and supervised the latter two therapists before and during the trial.

\section{Measures}

All the outcome measures assessed at baseline, at posttreatment ( 2 months after baseline), and at 5-month followup were collected using paper-and-pencil questionnaires. The following basic demographic information was collected at baseline: age, gender, citizenship, native language, education level, living arrangement, marital status, duration of wish for a child, previous infertility-related medical treatment, and history of psychological treatment. Then, 2 and 5 months later, demographic information was again collected with regards to medical treatment, supplementary psychological support, and pregnancy status.

The principal psychological outcome measures included the center for epidemiologic studies depression scale (CESD; Hautzinger 1988; Radloff 1997), the state-trait anxiety inventory (STAI; Spielberger et al. 1970), and the infertility distress scale (IDS; Pook and Krause 2002). The CES-D quantifies the severity of depressive symptomatology and consists of 20 items. Scores range from 0 to 60 , with scores of 16 or higher reflecting clinical depression (Hautzinger 1988). At baseline, Cronbach's alpha for the CES-D was 0.92. The STAI assesses general levels of anxiety and consists of 40 items. Scores above 33 (STAI-S) and above 35 (STAI-T) indicate clinically significant state and trait anxiety, respectively (Spielberger et al. 1970). At baseline, the Cronbach's alpha was 0.94 for state anxiety and 0.89 for trait anxiety. The IDS is an 11-item validated scale that assesses infertile patients' level of mental distress stemming from infertility. Representative items include: "How upset were you the last time you learned, despite your hopes, that you had not become pregnant?"; "How upsetting is your unfulfilled wish for a child at present?"; "How much distress do you currently experience at work?" and "How much distress do you currently experience in your relationship (aside from problems related to your unfulfilled wish for a child)?" IDS scores ranged from 0 (none at all) to 4 (very intense). A cut-off score of 21 indicated a clinically relevant level of distress (Pook and Krause 2002). In our sample, Cronbach's alpha was 0.73 at baseline. Pregnancy rate was defined as evidence of pregnancy according to clinical or ultrasound parameters (ultrasound visualization of a gestational sac; Zegers-Hochschild et al. 2006) and was assessed with patients' self-reports.

After finishing the treatment program, all participants were also asked to respond to a questionnaire assessing their level of acceptance of the treatment program (intervention group at post-assessment and control group at post-treatment). The research team developed the questionnaire on the basis of existing questionnaires used to assess acceptance of Internet interventions. It consisted of 20 items and asked participants to respond on a five-point Likert scale ( $1=$ not at all; $5=$ completely) to a series of questions surrounding their overall satisfaction with content, helpfulness, and Internet or program-related technical problems.

\section{Statistical analysis}

Group differences in demographic data, pre-test measures, and acceptance of treatment were analyzed using $t$-tests (two-tailed) and chi-square tests. Pre-post changes in outcome measures were analyzed using repeated measures analyses of variance. Post-follow-up changes within the intervention group and pre-post changes within the control group were evaluated using dependent $t$-tests (two-tailed). All calculations of within- and between-group effect sizes (Cohen's $d$ ) were based on the pooled standard deviation. Group differences in pregnancy rates were analyzed by calculating relative risks (RR; Rosenthal et al. 2000): A relative risk larger than one indicates a higher pregnancy rate for the intervention group versus the control group. For the 8week assessment, analyses were performed on an intentionto-treat basis. We calculated our results on a last observation carried forward basis (LOCF), replacing missing posttreatment values with pre-treatment values. In order to respond to concerns regarding the LOCF method, we counterchecked the data using mixed-model repeated measures ANOVA. Mixed-model repeated measures ANOVA 
uses all available data on each subject and does not involve the substitution of missing values. Potential confounding variables were checked before conducting the analyses for the main outcomes. The confounding variables were (1) current medical treatment, (2) participating as a couple or a single individual, and (3) gender (male-female).

\section{Results}

Sample characteristics

Table 1 shows a summary of the demographic characteristics at baseline arranged according to group. The majority of participants were female $(83.1 \%)$. The sample consisted of 11 couples in the intervention and 10 couples in the control group. Participants ranged between 22 and 45 years of age, with an average age of 33.5. The sample comprised 81 participants from Switzerland, 38 from Germany, and 5 participants from other countries ( 2 from France, 1 from Austria, 1 from the US, and 1 from the Netherlands). All participants were Caucasian. The mean duration of participants' wish for a child was 3.1 years (range 1-10 years), while $63.7 \%$ of the participants had made use of medical treatment before beginning with the Online Coaching treatment. Independent sample $t$-tests and chi-square tests revealed no significant differences between the participants in the intervention group and the control group with respect

Table 1 Demographic description of the participants and between-group comparison

\begin{tabular}{|c|c|c|c|c|c|c|c|}
\hline \multirow[t]{2}{*}{ Variable } & \multicolumn{2}{|c|}{ Treatment $(n=60)$} & \multicolumn{2}{|c|}{ Control $(n=64)$} & \multicolumn{2}{|c|}{ Total $(n=124)$} & \multirow[t]{2}{*}{$t$-value } \\
\hline & $n$ & $\%$ & $n$ & $\%$ & $n$ & $\%$ & \\
\hline \multicolumn{8}{|l|}{ Gender } \\
\hline Women & 49 & 81.7 & 54 & 84.4 & 103 & 83.1 & \multirow[t]{2}{*}{-0.399} \\
\hline Men & 11 & 18.3 & 10 & 15.6 & 21 & 16.9 & \\
\hline \multicolumn{8}{|l|}{ Age } \\
\hline Mean age & 34 & & 32.81 & & 33.50 & & \multirow[t]{2}{*}{1.814} \\
\hline Min-max & $23-45$ & & $22-44$ & & $22-45$ & & \\
\hline \multicolumn{8}{|l|}{ Occupational status } \\
\hline Full-time employed & 37 & 61.7 & 30 & 46.9 & 67 & 54.0 & \multirow[t]{6}{*}{-1.892} \\
\hline Part-time employed & 19 & 31.7 & 22 & 34.4 & 41 & 33.1 & \\
\hline Self-employed & 2 & 3.3 & 4 & 6.2 & 6 & 4.8 & \\
\hline Housewife & 1 & 1.7 & 2 & 3.1 & 3 & 2.4 & \\
\hline Student & 0 & 0 & 2 & 3.1 & 2 & 1.6 & \\
\hline Unemployed & 1 & 1.7 & 2 & 3.1 & 3 & 2.4 & \\
\hline \multicolumn{8}{|l|}{ Nationality } \\
\hline Switzerland & 35 & 58.3 & 46 & 71.9 & 81 & 65.3 & \multirow[t]{3}{*}{-0.267} \\
\hline Germany & 25 & 41.7 & 13 & 20.3 & 38 & 30.6 & \\
\hline Other & 0 & 0 & 5 & 7.8 & 5 & 4 & \\
\hline \multicolumn{8}{|l|}{ Education level } \\
\hline Apprenticeship & 13 & 21.7 & 17 & 26.6 & 30 & 24.2 & \multirow[t]{5}{*}{0.44} \\
\hline High school diploma & 9 & 15 & 10 & 15.6 & 19 & 15.3 & \\
\hline Professional school & 6 & 10 & 9 & 14.1 & 15 & 12.1 & \\
\hline University & 26 & 43.3 & 23 & 35.9 & 49 & 39.5 & \\
\hline Other & 6 & 10.1 & 5 & 7.8 & 9 & 7.3 & \\
\hline \multicolumn{8}{|l|}{ Duration of child wish } \\
\hline Mean duration (years) & 3.08 & & 3.5 & & 3.1 & & \multirow[t]{2}{*}{-0.197} \\
\hline Min-max (years) & $1-7$ & & $1-10$ & & $1-10$ & & \\
\hline \multicolumn{8}{|l|}{ Medical treatment } \\
\hline Yes & 40 & 66.7 & 39 & 60.9 & 79 & 63.7 & \multirow[t]{2}{*}{-0.788} \\
\hline No & 19 & 31.7 & 25 & 39.1 & 44 & 35.5 & \\
\hline \multicolumn{8}{|c|}{ Prior psychological treatment } \\
\hline Yes & 6 & 10 & 10 & 15.6 & 16 & 12.9 & \multirow[t]{2}{*}{0.929} \\
\hline No & 54 & 90 & 54 & 84.4 & 108 & 87.1 & \\
\hline
\end{tabular}


to demographic characteristics or any of the main outcome measures recorded at baseline. Infertile patients receiving medical treatment $(N=76)$ displayed significantly higher levels of infertility-specific distress at baseline $(t(117)=3.2, P<0.01)$ in comparison to infertile patients not receiving any medical treatment $(N=43)$. At baseline, our sample displayed high levels of mental distress across all measures: infertility-specific distress $(M=24.97$; $\mathrm{SD}=4.5)$, depression $(M=17.03 ; \quad \mathrm{SD}=10.7)$, state anxiety $(M=43.34 ; \mathrm{SD}=11.76)$, and trait anxiety $(M=43.32 ; \mathrm{SD}=9.66)$. In Switzerland, infertile patients must privately finance assisted reproductive treatments, whereas in Germany $50 \%$ of the costs of ART are covered by health insurance.

Adherence, questionnaires, and sessions completed

On average, each of the 52 intervention group participants who filled out the post-treatment measures completed approximately $79 \%$ of the Online Coaching program. Of these, half completed the entire self-help guide (13 sessions), 15 (28.8\%) completed 50\% or more, $10(19.2 \%)$ completed less than $50 \%$, and 1 participant $(1.9 \%)$ only completed the first session. As for the control group, the 41 participants who filled out the post-treatment measures completed, on average, approximately $72 \%$ of the program. In the control group, 18 (44\%) of the participants completed the entire self-help guide, $13(31.7 \%)$ completed $50 \%$ or more, and $10(24.4 \%)$ completed less than $50 \%$.

The average number of sessions completed (out of 13 sessions in total) by the intervention group participants was
$10.5(\mathrm{SD}=4.3)$, while the participants in the control group completed an average of $10.1(\mathrm{SD}=4.6)$ sessions. About $46 \%$ of all participants completed every session. The number of sessions completed did not correlate with pre-, post- or follow-up treatment scores for any of the outcome measures (all Spearman's rho $<0.1$; all $P \mathrm{~s}>0.5$ ).

\section{Main outcomes}

Table 2 shows the results for all outcome measures, including change scores with $95 \%$ confidence intervals and effect sizes. Although mean change scores were higher in the intervention group in comparison to the control group across all dimensions measured, repeated measures analysis of variance revealed that none of the group-time interactions were significant (IDS: $F(1,116)=2.75 ; P=0.10$, CES-D: $F(1,117)=1.99 ; P=0.16$, STAI-S: $F(1,117)=$ $0.01 ; P=0.93$, STAI-T: $F(1 / 117)=0.01 ; \quad P=0.92$ ). These non-significant results were confirmed in the mixedmodel repeated measures ANOVA. The corresponding between-group effect sizes (Cohen's $d$ ) were 0.16 for the IDS, 0.34 for the CES-D, 0.38 for the STAI-S, and 0.34 for the STAI-T. Within-group effect sizes for the intervention group were 0.78 for the IDS, 0.49 for the CES-D, 0.46 for the STAI-S, and 0.37 for the STAI-T. For the control group, the within-group effect sizes were 0.41 for the IDS, 0.26 for the CES-D, 0.40 for the STAI-S, and 0.39 for the STAI-T.

In order to check for potential confounding factors due to medical treatments, medical status was analyzed as a between-group factor. This analysis revealed that medical

Table 2 Psychological outcome measures at pre-, post-, and 5-month follow-up assessment, including change scores (with $95 \%$ confidence interval) and effect sizes $(n=119)$

\begin{tabular}{|c|c|c|c|c|c|c|c|c|c|}
\hline \multirow[t]{2}{*}{ Scale } & \multirow[t]{2}{*}{$n$} & \multirow{2}{*}{$\begin{array}{l}\text { Pre-treatment } \\
\text { score mean } \\
\text { (SD) }\end{array}$} & \multirow{2}{*}{$\begin{array}{l}\text { Post-treatment } \\
\text { score mean } \\
\text { (SD) }\end{array}$} & \multirow{2}{*}{$\begin{array}{l}\text { Pre-post } \\
\text { difference } \\
\text { mean }(95 \% \mathrm{CI})\end{array}$} & \multirow[t]{2}{*}{$n$} & \multirow{2}{*}{$\begin{array}{l}\text { Follow-up } \\
\text { score mean } \\
\text { (SD) }\end{array}$} & \multirow{2}{*}{$\begin{array}{l}\text { Pre-treatment } \\
\text { to follow-up } \\
\text { difference mean } \\
(95 \% \text { CI })\end{array}$} & \multicolumn{2}{|c|}{$\begin{array}{l}\text { Effect size pre-post } \\
(\text { Cohen's } d \text { ) }\end{array}$} \\
\hline & & & & & & & & $\begin{array}{l}\text { Within } \\
\text { group }\end{array}$ & $\begin{array}{l}\text { Between } \\
\text { group }\end{array}$ \\
\hline \multicolumn{10}{|c|}{ CES-D (range 0-60) } \\
\hline Treatment & 57 & $16.7(11.7)$ & $11.8(8.1)$ & $4.9(2.3-7.5)$ & 46 & $2.9(-0.9-6.6)$ & $2.9(-0.9-6.6)$ & 0.488 & \\
\hline Control & 62 & $17.4(9.7)$ & $14.8(9.6)$ & $2.6(0.5-4.7)$ & 41 & $5.4(1.8-9.0)$ & $5.4(1.8-9.0)$ & 0.264 & 0.337 \\
\hline \multicolumn{10}{|c|}{ STAI-S (range 20-80) } \\
\hline Treatment & 57 & $41.4(11)$ & $36.7(9.3)$ & $4.7(2.0-7.2)$ & 48 & $38.4(10.2)$ & $2.2(-0.7-5.4)$ & 0.461 & \\
\hline Control & 62 & $45.1(12.2)$ & $40.7(11.4)$ & $4.4(1.3-7.6)$ & 41 & $37.5(9.9)$ & $7.9(3.8-11.9)$ & 0.404 & \\
\hline \multicolumn{10}{|c|}{ STAI-T (range 20-80) } \\
\hline Treatment & 57 & $41.7(9.8)$ & $37.8(9.5)$ & $3.9(1.7-6.1)$ & 48 & $37.8(8.2)$ & $2.3(-1.9-6.4)$ & 0.373 & 0.383 \\
\hline Control & 62 & $44.8(9.4)$ & $41.1(9.9)$ & $3.7(1.9-5.6)$ & 41 & $37.3(7.8)$ & $8.4(5.9-10.8)$ & 0.388 & 0.338 \\
\hline \multicolumn{10}{|c|}{ IDS (range 0-44) } \\
\hline Treatment & 57 & $25.2(3.9)$ & $21.6(5.3)$ & $3.6(2.5-4.9)$ & 46 & $19.0(7.1)$ & $6.0(3.9-8.1)$ & 0.775 & \\
\hline Control & 62 & $24.7(4.9)$ & $22.5(5.7)$ & $2.2(0.7-3.6)$ & 41 & $18.9(5.7)$ & $6.1(4.1-8.0)$ & 0.412 & 0.163 \\
\hline
\end{tabular}

$C E S$ - $D$ center for epidemiologic studies depression scale, STAI-S state anxiety inventory, STAI-T trait anxiety inventory, IDS infertility distress scale 
treatments did not affect patients' outcome (e.g., no significant main effect of interaction with medical treatment was found). Participating as a couple, rather than individually, was also considered as a potential confounding factor. However, no significant main effect of interaction was found for participants who took part in Online Coaching as a couple. In addition, no significant gender differences were found regarding the efficacy of Online Coaching for mental health.

\section{Exploratory analyses of distressed participants}

An exploratory analysis was conducted with participants who exceeded the cut-off scores for the IBS and the CES-D at baseline, reflecting clinically relevant levels of infertility-related distress and depression. The rationale of this subgroup analysis was that only participants with clinically relevant pre-treatment levels of distress or depression could benefit from an intervention targeting psychological problems. Twenty-one participants in the intervention group and 28 participants in the control group exceeded both a score of 20 on the IBS and a score of 15 on the CES-D (Hautzinger 1988; Pook and Krause 2002). Repeated measures analysis (see Table 3) resulted in a highly significant interaction between intervention and control group of highly distressed patients with respect to the CES-D $(F(1,47)=8.82, P<0.01)$; however, no significant interactions were found in connection with the other measures (IBS: $F(1,47)=1.41 ; P=0.24$, STAI-S: $F(1,47)=0.42$; $P=0.52$, STAI-T: $F(1,47)=0.02, P=0.9$ ).
The corresponding between-group effect sizes were 0.67 for the CES-D, 0.20 for the IBS, 0.82 for the STAI-S, and 0.37 for the STAI-T. In this subgroup, within-group effect sizes of 1.55 (CES-D), 0.98 (IBS), 0.83 (STAI-S), and 0.55 (STAI-T) were found in the intervention group.

The results at follow-up

We examined the maintenance of treatment effects among members of the intervention group at the 5-month follow-up. Analysis of the intervention group's 5-month follow-up data revealed that the participants maintained the effects of their treatment for the entire period. While the improvements among participants were significant between pre- and postassessment (see Table 2: CES-D: $t(52)=2.8, P=0.007$; STAI-S: $t(52)=3.1, \quad P<0.01 ; \quad$ STAI-T: $t(52)=3.4$, $P<0.01$; IDS: $t(51)=5.7, P<0.01)$, no significant differences were found between post-assessment and follow-up $($ CES-D: $t(45)=-1.2, P=0.24$; STAI-S: $t(47)=-1.6$, $P=0.12 ; \quad$ STAI-T: $\quad t(47)=-0.99, \quad P=0.33 ; \quad$ IDS: $t(45)=1.3, P=0.21)$.

\section{Effects of treatment on pregnancy rates}

The post-treatment assessment ( 2 months after baseline) revealed no significant effect for Online Coaching on pregnancy rate when comparing the intervention to the control group (intention to treat: RR $0.79,95 \%$ CI: 0.19 , 3.30). At this point, three women (7\%) had become pregnant in the treatment group while six women $(9.4 \%)$ had

Table 3 Intention to treat analysis of patients with 21 or more on infertility distress scale (IDS) and 16 or more on Center for Epidemiologic Studies depression scale (CES-D) $(n=49)$

\begin{tabular}{|c|c|c|c|c|c|c|c|c|c|}
\hline \multirow[t]{2}{*}{ Scale } & \multirow[t]{2}{*}{$n$} & \multirow{2}{*}{$\begin{array}{l}\text { Pre-treatment } \\
\text { score mean } \\
\text { (SD) }\end{array}$} & \multirow{2}{*}{$\begin{array}{l}\text { Post-treatment } \\
\text { score mean } \\
\text { (SD) }\end{array}$} & \multirow{2}{*}{$\begin{array}{l}\text { Pre-post } \\
\text { difference } \\
\text { mean }(95 \% \mathrm{CI})\end{array}$} & \multirow[t]{2}{*}{$n$} & \multirow{2}{*}{$\begin{array}{l}\text { Follow-up } \\
\text { score mean } \\
\text { (SD) }\end{array}$} & \multirow{2}{*}{$\begin{array}{l}\text { Pre-treatment } \\
\text { to follow-up } \\
\text { difference mean } \\
(95 \% \mathrm{CI})\end{array}$} & \multicolumn{2}{|c|}{$\begin{array}{l}\text { Effect size pre-post } \\
(\text { Cohen's } d)\end{array}$} \\
\hline & & & & & & & & $\begin{array}{l}\text { Within } \\
\text { group }\end{array}$ & $\begin{array}{l}\text { Between } \\
\text { group }\end{array}$ \\
\hline \multicolumn{10}{|c|}{ CES-D (range 0-60) } \\
\hline Treatment & 21 & $27.8(7.9)$ & $14.8(8.8)$ & $13.0(8.8-17.3)$ & 18 & $17.1(9.1)$ & $10.0(4.0-16.6)$ & 1.548 & \\
\hline Control & 28 & $25.8(6.9)$ & $20.8(9.1)$ & $5.0(1.3-8.7)$ & 20 & $15.4(10.1)$ & $10.1(3.5-16.7)$ & 0.617 & 0.674 \\
\hline \multicolumn{10}{|c|}{ STAI-S (range 20-80) } \\
\hline Treatment & 21 & $48.0(11.4)$ & $39.0(10.1)$ & $9.0(4.3-13.7)$ & 18 & $41.6(11.3)$ & $6.1(1.4-11.6)$ & 0.833 & \\
\hline Control & 28 & $54.4(10.8)$ & $47.7(10.9)$ & $6.7(1.4-12.0)$ & 20 & $41.6(10.2)$ & $13.4(6.7-20.1)$ & 0.615 & \\
\hline \multicolumn{10}{|c|}{ STAI-T (range 20-80) } \\
\hline Treatment & 21 & $47.8(7.5)$ & $43.3(8.9)$ & $4.5(-0.08-9.0)$ & 18 & $41.1(7.2)$ & $6.6(0.3-13.1)$ & 0.549 & 0.821 \\
\hline Control & 28 & $50.7(8.7)$ & $46.6(8.9)$ & $4.1(1.2-7.1)$ & 20 & $38.5(8.9)$ & $13.3(8.3-18.3)$ & 0.466 & 0.371 \\
\hline \multicolumn{10}{|c|}{ IDS (range 0-44) } \\
\hline Treatment & 21 & $27.7(2.6)$ & $23.2(5.1)$ & $4.0(2.6-6.4)$ & 17 & $19.5(8.1)$ & $7.9(3.5-12.3)$ & 0.977 & \\
\hline Control & 28 & $27.1(2.6)$ & $24.3(5.7)$ & $2.8(0.8-4.9)$ & 20 & $18.8(7.7)$ & $8.2(4.5-11.9)$ & 0.632 & 0.20 \\
\hline
\end{tabular}

CES-D center for epidemiologic studies depression scale, STAI-S state anxiety inventory, STAI-T trait anxiety inventory, IDS infertility distress scale 
become pregnant in the control group. No additional comparison between the groups was possible at the 5-month follow-up since the control group had begun receiving the treatment following their waiting period, and no separate follow-up assessment was performed for the control group. A total of 15 women (31\%) from the intervention group became pregnant between the posttreatment assessment and the follow-up assessment, whereas three women $(6.8 \%)$ from the control group became pregnant during this period (Note: the control group began receiving the intervention between the postand follow-up assessments). By way of comparison, in Europe the success rate of ART for treating infertility ranges between 27 and 30\% (Nyboe Andersen et al. 2008).

\section{Acceptance of the treatment}

The participant feedback questionnaire gives information about the participant satisfaction and their assessment of the usefulness of the Child Wish Online Coaching program. Average levels of participant satisfaction were high. The mean of the total evaluation of the program was 4.0 $(\mathrm{SD}=0.75)$ out of a maximum of five, indicating a positive overall assessment of Online Coaching among participants. Subgroup analysis according to gender revealed a much more positive assessment of Online Coaching among females when compared to males. Male participants were significantly less satisfied with the Online Coaching program $(t(94)=3.300, P<0.01)$. However, these results are based on only 13 male participants.

\section{Discussion}

This study investigated the efficacy and patient acceptance of the first German-language Internet-based treatment for infertile patients. The results of our randomized controlled trial revealed no significant effects in the intervention group compared to the control group for any mental health outcome measures. One of the main reasons for failing to find significant between-group differences at post-assessment may be the lack of statistical power to detect small to medium effect sizes. Further, within-group improvements observed across all measures in the waiting-list control group attenuated between-group differences, which also helps to explain the lack of significant between-group differences. While the presence of such effects in the control group highlights the importance of controlling treatment condition for time and assessment effects-for example, by controlling for the regression-to-the-meansome of the improvements found in the control group may be related to its members experiencing positive effects due to their anticipation of treatment. Another explanation for the improvements in the control group may be that the control group members used other online information and support during the waiting phase.

Nevertheless, the effect sizes found in our trial are similar to the effect sizes that were found for the first webbased support program for infertile women $(d=0.24$ 0.47; Cousineau et al. 2008). Further, when compared to the efficacy associated with face-to-face psychological interventions for infertile patients, the effect sizes found for Online Coaching are comparable or even higher.

The sample included patients with high and low levels of distress and depression. When we limited our analysis to participants suffering from clinically relevant levels of distress and depression at pre-treatment, medium to large between-group effects for depression (CES-D: $d=0.67$ ) and state anxiety (STAI-S: $d=0.82$ ) were found. In addition, medium to large within-group effect sizes were found for all psychological measures (CES-D: $d=1.55$; IBS: $d=0.98$; STAI-S: $d=0.83$; STAI-T: $d=0.55$ ), while this difference was significant only for depression (CES-D). These findings are provocative, but were severely underpowered and need replication. At the same time, participants both high and low in distress were satisfied with the treatment and found it useful. Most participants (80\%) assessed their experience with Online Coaching as positive, suggesting that web-based formats are worth exploring.

The results of the present study showed no effect for Online Coaching on the pregnancy rates of infertile women. In general, studies are still inconclusive on the efficacy of psychological interventions with respect to pregnancy rates. Increased pregnancy rates have been reported in two meta-analyses (De Liz and Strauss 2005; Haemmerli et al. 2009), while another review (Boivin 2003) found no such effect on infertile women's chances of becoming pregnant. One simple explanation for our results is that the time between the pre- and post-assessments ( 8 weeks) may have been too short to reasonably expect any effect on the pregnancy variable. Other studies reporting of increased pregnancy rates following psychological interventions have assessed pregnancy rates after a year or longer (Domar et al. 2000; McQueeney et al. 1997). The present study is also clearly limited by the fact that the control group received the treatment following a waiting period, eliminating the possibility of comparing pregnancy rates at follow-up. All in all, further research is warranted that examines the possible effects of Internetbased psychological interventions on the pregnancy rates of infertile women when assessed approximately 1 year after baseline.

In our sample, infertile patients receiving medical treatment displayed significantly higher levels of infertil- 
ity-specific distress at baseline in comparison to infertile patients not receiving medical treatment. Thus, the sample's heterogeneity with respect to medical treatment may have lowered the effects found for Online Coaching in regards to mental health. Analysis for gender differences revealed no significant differences between infertile women and men in terms of the efficacy of the intervention for mental health. It is still unclear whether women and men benefit equally from psychological interventions (Boivin 2003; Haemmerli et al. 2009). In our study, the men were more critical and less satisfied with Online Coaching when compared with the women. This can possibly be explained by two factors: first, in several infertility studies, higher levels of mental distress were found in women when compared to men (Covington and Burns 2006; Wischmann 2005; Wright et al. 1991). Similarly, in our sample, only 3 of 21 men reported high levels of mental distress. Thus, men's good relative level of mental health may lead them to subjectively benefit less from Online Coaching in comparison to women. The second important factor is that women are typically more willing to look for and participate in psychological interventions (Boivin 2003), a trend that was further confirmed in the present study (women: $N=103$; men: $N=21$ ).

Limitations of the study and recommendations

for future research

There are several limitations suggested for our study. Our sample was not representative of typical infertile patients who seek traditional face-to-face support. The participants in our sample reported shorter durations of infertility, reported higher levels of distress, and were better educated than the general population (Haemmerli et al. 2009; Verhaak et al. 2007). Furthermore, selection bias could be present as the sample was composed of individuals who had expressed interest in our Internet-based treatment. Such factors limit our ability to generalize the results. In addition, using a waiting-list control group was suboptimal, as the psychological intervention's possible placebo effect was not controlled for. Using a placebo control group would have allowed us to identify the psychological effects specific to Child Wish Online Coaching. In future studies, it would also be important to assess control group participants' use of online information and support during the waiting period. Another limitation is presented by the fact that we did not differentiate between medical treatment types (for example, ART vs. diagnostic phases). Such differentiation is important since assisted reproductive treatments have been shown to be the most stressful form of treatment for infertility. Such patients often describe the phase between embryo transfer and pregnancy test as a particularly stressful period (Boivin and Takefman 1995; Klonoff-Cohen et al. 2001). Unfortunately, in our study, it was not possible to control for the various phases of medical treatment. In addition, information on the cause of participants' infertility was not collected. The time between pre- and follow-up-assessment- 5 months-may also have been too short to detect long-term effects on mental health. The intervention and the control group completed approximately 79 and $72 \%$ of the Online Coaching program. The main reason cited by participants for not completing the whole program was that its duration ( 8 weeks) was too short. Therefore, it would be useful to extend the duration of the Online Coaching to 10 weeks. Further, the present study likely did not have enough statistical power to test moderators. Only $17 \%$ of the total sample was composed of men. To date, there has been little research into the gender-specific effects of infertility or psychological interventions for infertile patients. In the future, women and men should be analyzed separately as there appear to be potential differences in their processing of fertility-related psychological support. Due to the dearth of male participants in our study, it was not possible to examine what additional benefits might be presented by both partners taking part in such Internet-based interventions. A couples-based approach to infertility therapy can address additional important aspects such as marital adjustment and sexual satisfaction, using therapy to facilitate communication between marital partners (Eunpu 1995).

\section{Conclusions}

A clear strength of our study was the high rate of participation. The demand for this type of online support is clearly evidenced by the registration of 165 participants in 3 months. Further, the study showed that infertile patients experiencing lower levels of mental distress were nevertheless also interested in this type of psychological support and were very satisfied with Online Coaching. Infertile patients may find Internet-based interventions less stigmatizing and more accessible than face-to-face interventions. Additionally Internet-based treatments may be more cost-effective than face-to-face inventions, and represent a small fraction of the costs associated with typical medical treatments. As a next step, the practicability and the effectiveness of the Online Coaching in routine clinical practice has to be verified. The results of our study confirm the promise of using Internet-based support to meet the treatment needs of infertile patients that needs more development and testing and show that such a support is appropriate for infertile patients independent of their levels of mental distress. 
Funding The present study was supported by a grant from the Swiss National Science Foundation (grant no. 325100-11375411).

\section{References}

Bents, H. (1991). Verhaltenstherapeutische Paartherapie bei Kinderwunschpatienten. In E. Brähler \& A. Myer (Eds.), Psychologische Probleme in der Reproduktionsmedizin. Jahrbuch der Medizinischen Psychologie (pp. 144-155). Berlin: Springer.

Boivin, J. (2003). A review of psychosocial interventions in infertility. Social Science and Medicine, 57, 2325-2341.

Boivin, J., Scanlan, L. C., \& Walker, S. M. (1999). Why are infertile patients not using psychosocial counselling? Human Reproduction, 14, 1384-1391.

Boivin, J., \& Takefman, J. E. (1995). Stress level across stages of in vitro fertilization in subsequently pregnant and nonpregnant women. Fertility and Sterility, 64, 802-810.

Campagne, D. M. (2006). Should fertilization treatment start with reducing stress? Human Reproduction, 21, 1651-1658.

Chan, C. H. Y., Ng, E. H. Y., Chan, C. L. W., Ho, P. C., \& Chan, T. H. Y. (2006). Effectiveness of psychosocial group intervention for reducing anxiety in women undergoing in vitro fertilization: a randomized controlled study. Fertility and Sterility, 85, 339-346.

Chen, T. H., Chang, S. P., Tsai, C. F., \& Juang, K. D. (2004). Prevalence of depressive and anxiety disorders in assisted reproductive technique clinic. Human Reproduction, 17, 23132318.

Cousineau, T. M., \& Domar, A. D. (2007). Psychological impact of infertility. Best practice \& research. Clinical obstetrics \& gynaecology, 21, 293-308.

Cousineau, T. M., Green, T. C., Corsini, E. A., Seibring, M. T. S., Showstack, M. T., Applegarth, L., et al. (2008). Online psychoeducational support for infertile women: a randomized controlled trial. Human Reproduction, 23, 554-566.

Covington, S. H., \& Burns, L. H. (2006). Infertility counseling. A comprehensive handbook for clinicians (2nd ed.). Cambridge: University Press.

De Liz, T. M., \& Strauss, B. (2005). Differential efficacy of group and individual/couple psychotherapy with infertile patients. Human Reproduction, 20, 1324-1332.

Domar, A. D., Clapp, D., Slawsby, E. A., Dusek, J., Kessel, B., \& Freizinger, M. (2000). Impact of group psychological interventions on pregnancy rates in infertile women. Fertility and Sterility, 73, 805-811.

Dunkel-Schetter, C., \& Lobel, M. (1991). Psychological reactions to infertility. In A. L. Stanton \& C. Dunkel-Schetter (Eds.), Infertility: Perspectives from stress and coping research (pp. 29-57). New York, London: Plenum Press.

Eugster, A., \& Vingerhoets, A. J. (1999). Psychological aspects of in vitro fertilization: a review. Social Science and Medicine, 48, 575-589.

Eunpu, D. L. (1995). The impact of infertility and treatment guidelines for couples therapy. The American Journal of Family Therapy, 23, 115-128.

Haemmerli, K., Znoj, H., \& Barth, J. (2009). The Efficacy of Psychological Interventions for Infertile Patients: A Metaanalysis Examining Mental Health and Pregnancy Rate. Human Reproduction Update, 15, 279-295.

Hautzinger, M. (1988). Die CES-D Skala. Ein Depressionsinstrument für Untersuchungen in der Allgemeinbevölkerung. Diagnostica, 34, 167-173.

Himmel, W., Meyer, J., Kochen, M. M., \& Michelmann, H. W. (2005). Information needs and visitors' experience of an internet expert forum on infertility. Journal of Medical Internet Research, 7, e20.

HONcode. (2009). Health on the Net Foundation. Available from: http://www.hon.ch. [2009 Aug 18].

Huang, J., Discepola, F., Al-Fozan, H., \& Tulandi, T. (2005). Quality of fertility clinic websites. Fertility and Sterility, 83, 538-544.

Jacobson, E. (1938). Progressive relaxation: A physiological and clinical investigation of muscular states and their significance in psychology and medical practice. Chicago: The University of Chicago Press.

Kahlor, L., \& Mackert, M. (2009). Perceptions of infertility information and support sources among female patients who access the Internet. Fertility and Sterility, 91, 83-90.

Kaluza, G. (2004). Stressbewältigung-Trainingsmanual zur psychologischen Gesundheitsförderng. Berlin: Springer Verlag.

Klonoff-Cohen, H., Chu, E., Natarajan, L., \& Sieber, W. (2001). A prospective study of stress among women undergoing in vitro fertilization or gamete intrafallopian transfer. Fertility and Sterility, 76, 675-687.

Levitas, E., Parmet, A., Lunenfeld, E., Bentov, Y., Burstein, E., Friger, M., et al. (2006). Impact of hypnosis during embryo transfer on the outcome of in vitro fertilization-embryo transfer: a case-control study. Fertility and Sterility, 85, 1404-1408.

McQueeney, D. A., Stanton, A. L., \& Sigmon, S. (1997). Efficacy of emotion-focused and problem-focused group therapies for women with fertility problems. Journal of Behavioral Medicine, 3, 313-331.

Nyboe Andersen, A., Goossens, V., Ferraretti, A. P., Bhattacharya, S., Felberbaum, R., de Mouzon, J., et al. (2008). Assisted reproductive technology in Europe, 2004: results generated from European registers by ESHRE. Human Reproduction, 23, 756-771.

Okamura, K., Bernstein, J., \& Fidler, A. (2002). Assessing the quality of infertility resources on the world wide web: tools to guide clients through the maze of fact and fiction. Journal of Midwifery \& Women's Health, 47, 264-268.

Pook, M., \& Krause, W. (2002). Ein Fragebogen zur infertilitätsbedingen Belastung. Reproduktionsmedizin, 18, 327-332.

Radloff, L. S. (1997). The CES-D scale. A self-report depression scale for research in the general population. Applied Psychological Measurement, 1, 385-401.

Randomization.com. (2008, March 22). Retrieved March 1, 2008, from http://www.randomization.com.

Rosenthal, R., Rosnow, R. L., \& Rubin, D. B. (2000). Contrasts and effect sizes in behavioral research: A correlational approach. New York, NY: Cambridge University Press.

Sachse, R. (2003). Klärungsorientierte Psychotherapie. Göttingen: Hogrefe.

Spielberger, C. D., Gorsuch, R. L., \& Lushene, R. E. (1970). Manual for the state-trait anxiety inventory. Palo Alto, CA: Consulting Psychological Press.

Stammer, H., Verres, R., \& Wischmann, T. (2004). Paarberatung und-therapie bei unerfülltem Kinderwunsch. Göttingen: Hogrefe.

Verberg, M. F. G., Eijkemans, M. J. C., Heijnen, E. M. E. W., Broekmans, F. J., de Klerk, C., Fauser, B. C. J. M., et al. (2008). Why do couples drop-out from IVF treatment? A prospective cohort study. Human Reproduction, 23, 2050-2055.

Verhaak, C. M., Smeenk, J. M. J., Nahuis, M. J., Kremer, J. A. M., \& Braat, D. D. M. (2007). Long-term psychological adjustment to IVF/ICSI treatment in women. Human Reproduction, 22, 305-308.

Wischmann, T. (2005). Psychosocial aspects of fertility disorders. Urologe, A44, 185-194.

Wischmann, T. (2008). Implications of psychosocial support in infertility-a critical appraisal. Journal of Psychosomatic Obstetrics and Gynecology, 29, 83-90. 
Wischmann, T., \& Stammer, H. (2006). Der Traum vom eigenen Kind. Psychologische Hilfen bei unerfülltem Kinderwunsch (3rd ed.). Stuttgart: Kohlhammer.

World Health Organization, WHO.(2002). Current practices and controversies in assisted reproduction. Report of meeting on "Medical, Ethical and Social Aspects of Assisted Reproduction" WHO Headquarters, Geneva, Switzerland, 1721 September 2001.
Wright, J., Duchesne, C., Sabourin, S., Bissonnette, F., Benoit, J., \& Girard, Y. (1991). Psychosocial distress and infertility: men and women respond differently. Fertility and Sterility, 55, 100-108.

Zegers-Hochschild, F., Nygren, K. G., Adamson, G. D., de Mouzon, J., Lancaster, P., Mansour, R., et al. (2006). The ICMART glossary on ART terminology. Human Reproduction, 21, 19681970. 